\title{
Freight and service parking needs and the role of demand management
}

\author{
Shama Campbell ${ }^{1 *}$ (D) José Holguín-Veras ${ }^{1}$, Diana G. Ramirez-Rios ${ }^{1}$, Carlos González-Calderón ${ }^{2}$, Lokesh Kalahasthi ${ }^{1}$ \\ and Jeffrey Wojtowicz'
}

\begin{abstract}
Purpose: This paper assesses the parking needs of freight and service related commercial activities and identifies the role of demand management in mitigating these needs.

Methods: To provide a context for the analyses, the authors selected two small commercial areas of about the same number of commercial establishments - one in Troy, NY, and the other in New York City-and applied freight and service trip generation models to estimate the total freight and service traffic generated at these sites. Then, using different assumptions of the amount of time these vehicles spend at a parking location, the authors estimated the number of parking spaces required by time of day under different assumptions of demand management.

Results: The results show that parking needs are proportional to the average parking durations. Essentially, the longer the duration the higher the parking needs. In terms of impacts on demand management, the results show that the 100\% Off-Hour Deliveries (OHD) program is expected to be the most impactful as it reduces the parking needs by $70-80 \%$ during peak hours. In second place, Staggered Deliveries reduces parking needs by about 60\% during the peak hours. The third place is occupied by the 30\% OHD Scenario and the Receiver-Led Consolidation programs, which are virtually tied, offering about $10-25 \%$ reduction.

Conclusions: The initial analysis revealed the importance of parking duration as it was shown to be proportional to parking needs; the longer the duration the higher the need for parking. The delivery simulation further bolstered this finding by showing that the optimal case occurs (i.e. minimizing parking duration) the closer the parking location is to the establishment. The further away the vehicle is parked the longer the walking time to the establishment, hence increasing the time the vehicle occupies the parking spot. The strategies applied to the case studies showed that Transportation Demand Management (TDM) strategies are effective in decreasing the number of parking spots needed during peak periods.
\end{abstract}

Keywords: Parking needs, Freight trip generation, Service trip generation, Freight demand management

\section{Introduction}

Local officials, transportation policy-makers, and traffic engineers frequently face the complex task of allocating capacity among the various users of transportation networks. This capacity allocation process takes different forms. One of them, road pricing, seeks to change the vehicular composition of the traffic by means of road user charges. After all, optimal pricing and optimal capacity allocation is essentially the same problem [1].

\footnotetext{
* Correspondence: campbs4@rpi.edu

'Department of Civil and Environmental Engineering, Rensselaer Polytechnic Institute, 110 8th St. JEC 4027, Troy, NY 12180, USA

Full list of author information is available at the end of the article
}

Another form of capacity allocation is vehicular access restrictions that limit access of some vehicles-frequently large trucks-to congested areas during the peak traffic hours. These types of access restriction initiatives may result in the addition of more trucks to the network, as the delivery still needs to be made to the receiver. The carrier will end up using multiple smaller trucks if unable to use a larger vehicle to complete the delivery. This may end up causing the opposite of what the strategy intends, resulting in increased congestion and negative environmental and economic impacts [2]. The allocation of parking among various user groups, such as passenger and commercial vehicles, is an example 
of a very common capacity allocation problem present in almost all urban areas.

In an ideal setting, this allocation would address the needs of all users in a way that maximizes economic welfare. Regrettably, for multiple reasons, this rarely happens. First, there is bias in the prioritization of the needs. It is a well-known fact that, for understandable political reasons, most decision-makers are very sensitive to the needs of passenger-related traffic; while being much less supportive of the needs of freight and service activity (FSA). This is reflected in the adage "freight doesn't vote", frequently used by freight advocates to explain the tendency of decision-makers to disregard the needs of freight activity. As a result, addressing the needs of the traffic associated with pick-up and delivery of cargo and the ones related to the provision of services at commercial establishments and households are relegated to lower priorities. A second reason is the profound lack of awareness of the magnitude, scope, and importance of FSA; which leads to a situation where well-meaning decision-makers may not even be aware of the needs of FSA, or may honestly perceive that these needs are being met in other ways.

Regardless of the reason, the evidence suggests that the parking needs of FSA are not being fully met. For instance, researchers have found that, in Manhattan, there are ten ZIP codes where the demand for parking space is larger than the linear capacity of the streets [3], let alone the needs for FSA. Anecdotal evidence provided by companies with operations in multiple cities suggests that the lack of suitable parking for FSA is a common problem in commercial areas in midsize and large cities. Addressing this problem is extremely important for both environmental and economic reasons. To start, FSA plays a crucial role in urban economies as these sectors supply the goods and services required for cities to function. If FSA stop, urban economies rapidly come to a halt. A second important reason to satisfactorily address the problem is that FSA vehicles must park close to their customers. A driver that is delivering 200 pounds of supplies, or a technician that is replacing the motor in an air conditioning unit in a building, cannot park far away. If these individuals cannot find suitable parking they circle around the block until they find a parking spot. If they cannot find parking, they run the risk of missing the time window set by the customer, or determined by the job schedule they have. Faced with the prospect of upsetting the customer by missing the time window, and even losing business, it seems quite rational to simply double-park in front of the customer and run the risk of a parking infraction. The bottleneck created by this decision, in turn, generates additional congestion and pollution. Unsurprisingly, researchers have found that increasing the amount of parking available for FSA reduces congestion [4].
The quantification of demand for the various user groups is indispensable for optimal allocation of capacity. Regrettably, the amount of research on FSA demand is very small as most of the work has focused on passenger activity. As a result, practitioners are frequently unable to readily estimate the magnitude of the FSA in their jurisdictions and predict their future levels of activity with some degree of accuracy. This, in turn, makes it very difficult to find effective solutions that could help improve FSA operations and to plan much needed network improvements. In the case of parking allocation, a key input is trip generation analysis that estimates the number of vehicles that arrive and depart from a given area. The number of vehicle trips made by time-of-day, together with estimates of the amount of time the vehicles spend at a given parking place provide the data needed to assess parking needs.

Of interest to this paper is the assessment of the parking needs for commercial activities, like those related to freight pick-ups and deliveries and service activities associated with the work of photocopier technicians, window cleaners, and others. The parking needs of passenger vehicles with commercial license plates are not within the scope of the research reported in this paper.

The main objectives of this paper are: (1) to gain insight into FSA parking needs and optimal parking provision; and (2) to assess the potential effects of alternative Transportation Demand Management (TDM) strategies in reducing these parking demands. As part of the research, the authors selected two small case studies from New York City and Troy, New York and used the freight trip generation (FTG) and service trip attraction (STA) models from the National Cooperative Freight Research Program (NCFRP) Project 25(01) "Estimating Freight Generation Using Commodity Flow Survey Microdata" to estimate the number of vehicle trips generated by FSA; assumed realistic values of the average parking time of freight and service vehicles; computed the numbers of parking spaces required for freight and service vehicles to conduct their activities; and assessed the impacts of alternative strategies to reduce the demand for parking [5].

The remainder of the paper is organized as follows. Section 2 contains a basic literature review. Section 3 provides a summary of the data used. Section 4 introduces the modeling approach. Section 5 describes the case studies. Section 6 presents the results of the analysis and possible policy implications while Section 7 provides concluding remarks.

\section{Basic literature review}

Freight and service vehicle trips are the result of the economic activities performed at business locations. These vehicle trips, with freight typically generating the largest portion, produce negative impacts on society 
such as emissions of local pollutants and Greenhouse Gases (GHG), noise, and congestion, and are also a major consumer of natural resources. Thus, it is important to incorporate FSA in transportation decision-making to increase the efficiency of the network. However, lack of research and knowledge in understanding FSA is posing a great challenge to public sector and transportation agencies in planning, assessing, and forecasting the impacts of the associated vehicle traffic.

The passenger transportation demand literature makes a distinction between two key metrics: the number of passenger trips produced and attracted, and the number of vehicle trips required to transport the passenger trips [6]. In contrast, the traffic engineering literature mostly focus on vehicle trip generation which is what matters the most in traffic impact analyses. Probably, the largest compilation of this kind of models is the Trip Generation Manual [7] which contains hundreds of models as functions of land use. In the case of FSA, the relevant metrics are: freight generation (FG) - the amount of cargo a commercial establishment generates measured by a unit of weight, typically pounds/day or tons/day; freight trip generation (FTG) - the number of freight vehicle trips generated by an establishment; and service trip generation (STG) the number of service vehicle trips generated by an establishment. Each of these can be further decomposed into attraction and production. Attraction is all incoming flow whether cargo or vehicle trips to the establishment plus the vehicle trip that leaves the establishment after performing a delivery or service. Production is the outgoing flow of cargo or vehicle trips leaving the establishment, plus the vehicle trip returning to the establishment after conducting a delivery or service at another location [6]. Reflecting the lack of research on FSA, the existing compilations of FTG models are much smaller than the massive ITE Trip Generation Manual $[8,9]$.

To model the various FSA metrics that could possibly be used, researchers have used different approaches, including econometric models [10]. The modeling approaches in the studies focusing on FSA in the United States have been similar to those studies done in other countries. Some studies done in European countries such as the Netherlands, France and England have utilized similar modeling techniques and variables because businesses regardless of location will need similar components in order to operate [11-13]. Modeling approaches have explored both aggregate and disaggregate models for various geographic scopes, such as, international, intercity (interregional), and urban [14-16]. Studies that have focused on the estimation of FTG for urban areas, which are typically plagued with parking scarcity issues, have done so for midsize as well as large urban areas $[17,18]$. In the estimation of FTG models, empirical studies have also identified key independent variables. Key explanatory variables used in the estimation of FTG models include economic activity, employment, commodity type, line of business and establishment area [11, 19-21]. Some studies considered employment, industry segment and commodity transported [22]. Others used land use variables [23-25] in addition to employment size, business industrial class, truck ownership, land use class, and land value [26]. Studies have undertaken more complex estimations of FTG [27], while others have introduced simpler models that are able to efficiently predict FTG by using one explanatory variable, mainly employment $[28,29]$.

The literature on service trips is the most limited of all. Service trips are called as such because their main purpose is to perform a service activity; for example, machine repairs/installations, and maintenance/cleaning of premises. Some service trips may contain a component of freight as they may pick-up or drop-off equipment or machine parts for example, but due to the definition previously stated are still classified as service trips. Two key aspects of service trips that differ from freight trips are: (1) the time spent at the receiving establishmentservice trips typically take a longer time to complete, this has implications on parking; and (2) vehicle type usedservice trips tend to use smaller vehicles which may not be easily identified, and as such may be mistaken for passenger vehicles [30]. Browne and Wigan [31] estimated that one third of the total commercial vehicle trips are services for small-scale firms $(<60$ employees), while for larger firms ( $>60$ employees), service trips constitute one fourth of the total commercial vehicle trips received.

More recently, a new generation of FTG models were estimated as part of NCFRP Project 25 "Freight Trip Generation and Land Use" [32]. These models are a major departure from the tradition of estimating FTG as a function of land use variables, such as square footage. Instead, the models use industrial classification systems, i.e., North American Industry Classification System (NAICS), as the overall framework, and employment as the key independent variable. These changes led to significant increases in the ability of the models to predict FG/FTG. The resulting models outperform the others in the literature [33]. A second phase of the project, NCFRP 25(01), expanded the original work via: (1) the estimation of FG models using the Commodity Flow Survey microdata; (2) the estimation of service trip attraction (STA) models using newly collected data by the project; and (3) the estimation of additional FTG models [5].

The FTG and STA models from NCFRP 25(01) are important for several reasons. First, because of their disaggregate nature, their estimates could be aggregated to larger groupings in terms of industry and/or geography (e.g., ZIP code, transportation analysis zones). Second, since they are based on industrial classification systems, 
they could be folded into any land use classification system. Third, they are more accurate than the models available in the literature. These models are well-suited for the analyses of FSA parking needs.

As cities grow larger, the issue of parking becomes more evident. A few leading local and regional governments around the world have started to make significant changes in their parking policies, which have impacted the cities' economic growth, while benefiting the environment and the communities' quality of life. These parking policies range from parking law enforcement (restricted areas, time restrictions, and limited number of spaces available) to more innovative actions (parking guidance systems). The current state of parking policies in most cities in the United States has been discussed by the Institute of Transportation and Development Policy [34]. In other parts of the world, these and other innovative measures have been applied to parking in urban areas, such as on-street parking locking devices (Charleroi), "park and ride" (P\&R) facilities (Cologne, Oxford, Utrecht and München), parking guidance systems (Gothenburg, Zurich, Charleroi), no-square parking (Gothenburg), user rights parking in form of badges (Zurich), among others [35].

Of interest to this research is the state of practice on parking policies for commercial vehicles. For more than a decade, studies have been developed with respect to parking management of commercial vehicles. On-street parking facilities for trucks were incorporated in an experimental study with truck drivers in Japan to understand the attitudes towards the implementation of these regulations [36]. Solutions to commercial vehicle parking have been related to land use management, public infrastructure, access conditions, traffic management, enforcement and promotion, as discussed in [37]. An example of strict parking enforcement as a way of regulating freight traffic is the NYC Department of Transportation, that implemented a number of parking restrictions, including standing time limits (no more than three hours parking) and requiring commercial vehicles to park close to the curb so as to not occupy more than $10 \mathrm{ft}$. of roadway space from nearest curb. These restrictions were applied between 7 am and $7 \mathrm{pm}$, Mondays through Saturdays for commercial vehicles in Midtown Manhattan [38]. The Park Smart Project, also in New York City, has also been implemented to make parking easier, where they provided an escalating parking rate structure. Other innovative transportation demand management policies were suggested by Holguin-Veras and others [39], which aimed to solve the freight traffic issues in New York City. One of these solutions, the Off-hour Delivery (OHD) Program was analyzed as a way of mitigating the parking problem in the city [3]. In Washington D.C., other examples of innovative solutions were discussed for the use of downtown curbsides for freight delivery [40]. In San Francisco, the shared spaces approach was used to optimize the parking slot allocation, where pedestrians and delivery trucks shared platforms, such as the on-street loading bays. As cited by the authorities, "more than half of the curbside spaces in the downtown core are reserved for commercial loading activities [41]". A more recent classification of specific parking related solutions were discussed in $[4,42]$.

In other parts of the world, parking needs for commercial vehicles have been accounted for by practitioners as well as by the different transportation authorities. In the Netherlands, regulations have been provided to restrict commercial vehicle parking in residential areas; to accommodate for this, the authorities have provided secured parking spaces for commercial vehicles [35]. The "Best Urban Freight Solutions" a compilation of best practices in Europe, includes a number of recommendations $[43,44]$. For instance, a number of these best practices were implemented in Barcelona, where there are approximately 25,000 vehicles conducting about 100,000 daily loading and unloading operations, curbside management and integration mechanisms were implemented to provide access to specific zones in the city [45]. The PIARC report provides seventeen case studies developed in different countries (Belgium, France, Japan, Norway and UK), where a solution that integrates ITS with parking management has been tested in Toyota City, where truck drivers were able to remotely book their parking spaces through their phones [46].

\section{Data description}

The data used in the case studies were collected via survey at two locations: 1) a small commercial center located in the metropolitan area of Troy, New York which contained 19 businesses; and 2) a commercial area used in the SoHo area in lower Manhattan in New York City which provided data from 21 businesses. The details of these datasets are discussed in more detail in the case study section of this paper. The survey used to collect the data was developed from the template presented in the NCFRP 19 Report "Freight Trip Generation and Land Use" [32]. The survey collected data on business characteristics such as employment and type of business as well as FSA at each establishment.

The FTG and STA models used in this paper were estimated with data collected, during the two phases of NCFRP 25, from the New York City (NYC) metropolitan area, and the New York State Capital Region (CR) where the city of Albany is located. The survey had three sections with questions about deliveries and service trips, and current operations and flexibility. In relation to FG and FTG, the data collected included: number of deliveries received, number of shipments sent out, 
typical size and weight of deliveries and shipments, types of commodities received and shipped, among others. In relation to STA, the data collected included: the number of service trips received and duration on the service activity. Data were also collected on the businesses' current operations and flexibility, including number of employees at the establishment, both full-time and part-time, which were particularly important for this analysis.

The descriptive statistics of the data revealed that the majority $(77 \%)$ of the sample received ten deliveries or less per day. Most of the sample (approximately 70\%) revealed that they also send shipments from their establishments; a majority of which $(60.5 \%)$ are ten shipments per day or less. With regards to freight attraction (FA), almost $30 \%$ of the sample receives cargo of 20 pounds or less per delivery with another approximate $20 \%$ receiving between 21 to 100 pounds. The pattern of shipment size varied by industry type. For example, manufacturing (NAICS 31-33) deliveries are typically larger while for wholesale (NAICS 42) and retail (NAICS 44) delivery sizes tend to be smaller in comparison. As for freight production (FP), approximately 40\% send out shipments of 20 pounds or less and another approximately 16\% making shipments that are between 21 to 100 pounds. In the case of shipment size, the trend seems to be consistent across most industry types within the sample as the majority sent out shipments of 20 pounds or less.

\section{Modeling approach}

The modeling approach used by the authors in NCFRP 25 emphasized practicality, a particularly important criterion because the resulting models were expected to be ready-to-use. As a result, even though freight activities are influenced by numerous economic factors and logistical decisions, the models estimated use employment as the sole independent variable. Among other reasons, the data needed to estimate more advanced and accurate FTG models are not readily available [24]. However, it should be noted that these relatively simple models provide fairly solid estimates of FG/FTG/STA at the establishment level. In order to account for the part-time and full-time employment, a new variable-Full Time Equivalent (FTE) employment-defined as the summation of the number of full-time employees plus 0.45 times the number of part-time employees-was created. Interaction variables were also generated to differentiate between geographical zones and industry sectors. Models which were statistically significant and conceptually valid were kept.

In general terms, both linear and non-linear models were estimated. The functional forms found most useful are shown in Eqs. (1) and (2). Depending on the statistical significance of the parameters, the final model could take a reduced form of the original ones.
Linear:

$$
f_{i}=\alpha+\beta E_{i}
$$

Non-linear (Power):

$$
f_{i}=\alpha^{*} \times E_{i}^{\beta}
$$

Where:

$f_{i}=$ FSA metric for establishment $i$

$\alpha=$ constant

$\beta=$ employment coefficient

$E_{i}=$ employment at establishment $i$

$\alpha^{*}=$ constant with $S^{2}$ adjustment $=e^{\alpha+\frac{s^{2}}{2}}$

The authors used the data to estimate FG/FTG/STA models for 2-digit NAICS codes using Ordinary Least Squares (OLS) and weighted OLS (WLS). At the end of the process, the authors estimated: (1) 62 freight trip production and 70 freight trip attraction models for 12 industry sectors; (2) 118 service trip attraction modelsthe first such models reported in the literature, for 21 industry sectors (due to the budget constraint, data about service trip production were not collected); and (3) 49 freight production and 50 freight attraction models for 11 industry sectors. The FTG and STA models used in the paper come from the second phase of the project-NCFRP 25(01) [5].

The freight and service trip models were estimated for different industry sectors for three subsamples: 1 . New York City (NYC), 2. Capital Region (CR) and 3. Combined data set containing both NYC and CR observations. The non-linear (log-log) form shown in Eq. (2) typically had the higher explaining power, where the coefficient $\beta$ represents the elasticity of trips per day with respect to the employment. In the case of the FTP models for the combined datasets of NYC and CR, for all sectors estimated the elasticity varies from 0 to 0.89 , showing an inelastic behavior. Construction (0.89) and retail (0.73) sectors have the highest elasticities. While wholesale (NAICS 42) and transportation support activities (NAICS 48) sectors both have zero elasticity. For the aggregate FTP model with all sectors, the model shows an elasticity of 0.54 , close to 0.5 -which means the FTP is proportional to square root of employment. The elasticities of the FTA models for different sectors vary from $0.27-0.60$, also displaying inelastic behavior. The FTA of wood, paper manufacturing (NAICS 32) is more elastic to employment $(0.60)$ while the construction (NAICS 23) sector is the least elastic (0.27). FTA for all sectors together display an elasticity of 0.43 . On average, the FTP of NYC is more elastic (0.56) compared to that of CR (0.49) while in the case of FTA, CR (0.64) shows more elastic behavior compared to that of NYC 
(0.38). This means that compared to $\mathrm{CR}$, for a $1 \%$ increase in employment, the relative increase in FTP in NYC is more but the relative increase in FTA is less. These values do not lead to any valid conclusions on FTG behavior between CR and NYC due to data constraints, as all freight intensive sectors were not covered in the case of CR. The FTG models have also been assessed in terms of transferability, both through external validation cases and by comparing to FTG rates available in literature [33].

Linear models shown in Eq. (1) typically provided the higher explaining power for STA, where the coefficient $\beta$ represents the marginal effect of STA per day with respect to the employment. In the case of combined models for CR and NYC except for construction (NAICS 23), retail (NAICS 44-45), transportation support activities (NAICS 48), real estate (NAICS 53), and accommodation and food services (NAICS 72) sectors, all remaining sectors have zero marginal effect; this means that the STA is constant irrespective of employment. Among sectors with a constant STA, the STA per day varies from 0.17 to 1.18 , with the health care (NAICS 62) sector being the highest. The accommodation and food services (NAICS 72) sector has the highest marginal effect (0.022). STA between NYC and CR behave differently among the industry sectors. For CR, the wholesale (NAICS 42), retail (NAICS 44-45), information (NAICS 51), and health care (NAICS 62) sectors have zero marginal effects while in NYC these sectors have a positive marginal effect. The aggregate model for STA for all sectors shows higher marginal effects for CR (0.012) than for NYC $\left(4 \times 10^{-4}\right)$; which means that a unit increase in employment will result in a larger increase in STA for CR than in NYC. This makes sense because for a given establishment (land/building) size, NYC should have a larger number of employees compared to $C R$ and the service trips are typically regular maintenance that depend mostly on the building size/area not on the employment.

\section{Case studies}

To assess the FSA parking needs, the authors selected two small case studies from two different urban conditions. One is a small commercial center located in Troy, New York; while the other corresponds to commercial establishments located in a section of SoHo in Lower Manhat$\tan$. The analyses of the results for these commercial areas-with about the same number of establishmentsprovide an idea about the range of the FSA parking needs in American cities. It is worthy to note that the model estimations assume that the demand from each receiver results in a truck trip. In reality, this may not always be the case as one truck may serve more than one receiver from one trip. This dynamic is not accounted for in this analysis as it is difficult to determine this portion of deliveries where this overlap occur. Therefore, in this case, we are modeling the worst case scenario of each delivery resulting in a separate truck trip.

Troy, NY is one of the cities comprising the Capital District region centered around the City of Albany, the capital of the State of New York. It is a middle-sized city with a more sprawled land use pattern that is not very dense in population with a land area of 11 mile $^{2}$ $\left(28 \mathrm{~km}^{2}\right)$ and a population of about fifty thousand [47]. Troy, NY houses approximately 1400 establishments in various industries based on 2014 Census Data [48]. New York City (NYC), on the other hand, is a much larger and denser city both in population and land use pattern. Manhattan, the densest of the boroughs, which is the focus of this case study has a land area of 22.83 mile $^{2}$ $\left(59.13 \mathrm{~km}^{2}\right)$ and a population of over 1.6 million [47]. This borough is the center of the economic activity of (NYC) and one of the largest economic centers in the world with over five hundred thousand establishments according to the 2014 Census Data [48].

\subsection{Case study \#1: commercial center in Troy, New York}

This commercial center, located in Troy, NY, is used as a representative of the strip malls that dot the suburban landscape in the US. The majority of the 19 businesses in the strip mall are in the retail sector (NAICS 44-45) and accommodation and food services (NAICS 72). The remaining establishments are in finance and insurance (NAICS 52); real estate and rental and leasing (NAICS 53); professional, scientific, and technical services (NAICS 54); and other services except public administration (NAICS 81). Field surveys were conducted to obtain the employment estimates for each establishment, which is the input needed for the models. As shown in pane (a) of Fig. 1, the commercial center has plenty of parking available (a total count of 238). However, since the paper's objective is to get an idea about the FSA parking needs for strip malls, using the data from this commercial center is an acceptable decision.

\subsection{Case study \#2: SoHo in New York City}

The commercial area used in this case study is located in the SoHo area in Lower Manhattan. Twenty-one commercial establishments were surveyed, to obtain employment and other data related to FSA at their businesses. The businesses were in the retail industry (NAICS 44) with 19 retail stores, the majority being clothing and accessories stores, and the remaining two belong to the food services sector (NAICS 72). In most cases, these are high-end stores where customer attention is a central element of their business strategy. Due to the extremely high land values, the amount of storage space is minimal or non-existent. In terms of parking 


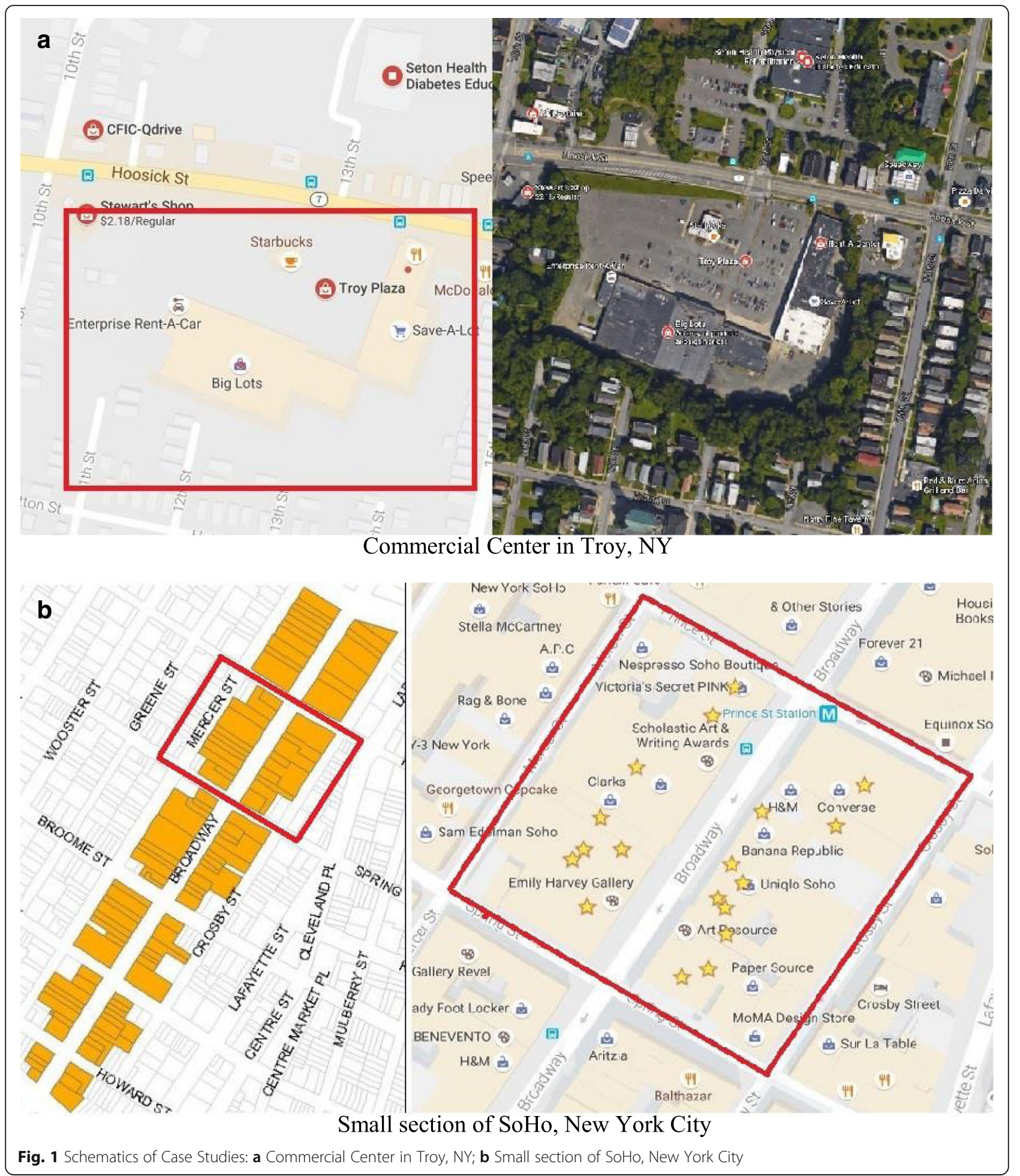

supply for FSA, this case is significantly less encouraging as the businesses do not have off-street parking. On-street parking is the only option. In the area in front of the stores, the FSA parking supply (assuming an average vehicle size of $10 \mathrm{~m}$ ) for commercial vehicles-which include FSA vehicles, and passenger vehicles with commercial license plates-is estimated to be 28 (none are exclusively allocated to freight deliveries). To consider the fact that drivers may be willing to park within a reasonable distance from the delivery location, the authors 
also estimated the parking supply for an area of one block away in all directions around the target study area in pane (b) of Fig. 1. The total number of on-street parking spots for all commercial vehicles is estimated to be 125 , with another 12 spots allotted for exclusive use of delivery trucks from $7 / 8$ am to $10 \mathrm{pm}$ (137 in total). Obviously, these parking spots would also be used by other businesses nearby, not just by the ones in the target area.

\section{Results and policy implications}

This section presents the results obtained for both case studies. The section starts with the estimation of the FSA traffic generated, which is then used to assess the corresponding parking needs for different assumptions of parking times. Later in the section, the authors use different scenarios of Transportation Demand Management (TDM) strategies to assess the corresponding impacts on FSA parking needs.

The application of FTA and STA models indicated that the total FSA traffic generated at the commercial center in Troy, is comprised of a FTA of 48.02 daily trips and a STA of 6.81 daily trips (for computation purposes, these values are not rounded as they influence the parking needs). For the SoHo area, the estimate for total FTA is 127.57 daily trips and for STA is 7.72 daily trips. The significant difference in FSA traffic is the direct result of the difference in levels of business activity, as the stores in SoHo are on average several times larger than the ones in Troy. To compute parking needs, one needs to have an idea about the temporal distribution of FSA trips in the area and the amount of time each activity takes. In the absence of hard data, estimates were obtained using informal interviews with carriers.

The number of parking spaces needed for FSA activity were calculated assuming that: (1) about $25 \%$ of the total FTA takes place during peak hours (7 am - 8 am), about $63 \%$ of the total FTA takes place between 6 am and noon and approximately 33\% from noon to $7 \mathrm{pm}$, (2) service trips are uniformly distributed during normal office hours except from 7 am to 9 am where about $25 \%$ of total STA takes place $[3,49]$. In terms of the amount of time parked at a given location, the authors assume that freight vehicles making deliveries and service vehicles occupy the space for a period of $0.5 \mathrm{~h}$ and $1.5 \mathrm{~h}$ respectively, in the base case condition. It should be noted that this time includes the time to organize the work and/or unload the cargo, walk to the customer location, deposit the goods or perform the service, walk back to the vehicle, and load the vehicle to leave.

\subsection{Impacts of parking duration}

Table 1 presents a sensitivity analysis to assess the impacts of changes in parking duration on the parking needs for FSA vehicles. In addition to the base values of 0.5 and $1.5 \mathrm{~h}$, the authors considered two additional scenarios. In the "minimum" scenario, the parking durations are set to the lowest practical values, i.e., 0.25 and $0.75 \mathrm{~h}$. In the "maximum" scenario, the parking durations were set to 2 and $6 \mathrm{~h}$, as averages for freight and service respectively. The most obvious result is that in the case of SoHo, the existing parking supply allocated for use of freight vehicles is inadequate. The heart of the issue is that the parking spaces dedicated to commercial vehicles are occupied by the numerous passenger vehicles with commercial license plates.

The results show that parking needs are heavily influenced by the average parking durations. Essentially, the longer the duration the higher the parking needs. This seemingly obvious result has important policy implications for parking location and allocation. As stated before, the parking duration is influenced by the time spent walking from the vehicle to the customer (and back). It follows that the shorter the vehicle-to-customer distance, the shorter the parking duration and the lower the parking needs. The implication is that allocating "local" parking for FSA is more efficient than "centralized" parking that is farther away.

Table 1 Total freight and service vehicle parking needs

\begin{tabular}{|c|c|c|c|c|c|c|c|c|c|}
\hline \multirow{2}{*}{$\begin{array}{l}\text { Measure } \\
\text { of FSA }\end{array}$} & \multirow{2}{*}{$\begin{array}{l}\text { Trips/ } \\
\text { Day }\end{array}$} & \multirow{2}{*}{$\begin{array}{l}\text { Peak hour } \\
\text { as } \% \text { of total }\end{array}$} & \multirow{2}{*}{$\begin{array}{l}\text { Vehicles/hr. } \\
\text { (peak hour) }\end{array}$} & \multicolumn{2}{|l|}{ Minimum } & \multicolumn{2}{|l|}{ Average } & \multicolumn{2}{|l|}{ Maximum } \\
\hline & & & & $\begin{array}{l}\text { Parking } \\
\text { time (hours) }\end{array}$ & $\begin{array}{l}\text { Parking } \\
\text { spaces/ hour }\end{array}$ & $\begin{array}{l}\text { Parking } \\
\text { time (hours) }\end{array}$ & $\begin{array}{l}\text { Parking } \\
\text { spaces/ hour }\end{array}$ & $\begin{array}{l}\text { Parking } \\
\text { time (hours) }\end{array}$ & $\begin{array}{l}\text { Parking } \\
\text { spaces/ hour }\end{array}$ \\
\hline \multicolumn{10}{|c|}{ Commercial Area- Downtown New York City, NY } \\
\hline FTA & 127.57 & $25.00 \%$ & 31.89 & 0.25 & 7.97 & 0.50 & 15.95 & 2.00 & 63.79 \\
\hline STA & 7.72 & $12.50 \%$ & 0.97 & 0.75 & 0.72 & 1.50 & 1.45 & 6.00 & 5.79 \\
\hline Total & 135.29 & & 32.86 & & 8.70 & & 17.39 & & 69.58 \\
\hline \multicolumn{10}{|c|}{ Commercial Center - Troy, NY } \\
\hline FTA & 48.02 & $25.00 \%$ & 12.01 & 0.25 & 3.00 & 0.50 & 6.00 & 2.00 & 24.01 \\
\hline STA & 6.81 & $12.50 \%$ & 0.85 & 0.75 & 0.64 & 1.50 & 1.28 & 6.00 & 5.11 \\
\hline Total & 54.83 & & 12.86 & & 3.64 & & 7.28 & & 29.12 \\
\hline
\end{tabular}


To assess the impacts of parking location, the authors conducted a simplified simulation based on the SoHo case. To this effect, the total FSA traffic is assumed to be homogenously distributed across the 21 stores within the SoHo sample. The simulation considers four scenarios of available parking, which is assumed to be located: (1) center of storefront block; (2) end of storefront block; (3) one block away; and (4) two blocks away. The walk times from each store to the parking location are computed using a travel speed of $1.4 \mathrm{~m} / \mathrm{second}$. If intersections have to be crossed, a waiting time of $1 \mathrm{~min} /$ intersection is added. The preparation time at the vehicle, associated with loading/unloading/packing, and the time required to make a delivery or pick-up are both assumed to be $10 \mathrm{~min}$ (constant for all scenarios). The results indicate that locating the parking in the middle of the block is optimal in terms of parking needs as it reduces the walk time to the minimum. Locating the parking at the end of block increases parking time by about $4 \%$ though it eases parking maneuvers. The largest impacts are in the cases where the parking is farther away as the parking time increase by $44 \%$ (one block away) and 79\% (two blocks away). The bottom line is that cities have a vested interest in ensuring that parking for FSA is provided at the locations where it is needed the most. Interestingly, the private interest of carriers and transportation agencies are perfectly aligned.

\subsection{Impacts of demand management}

Another way to reduce parking needs is to reduce the vehicle traffic by using TDM techniques. TDM is defined by Holguín-Veras and Sánchez-Díaz [50] as "...the area of transportation policy that seeks to induce the demand generator to enact changes in demand patterns to increase economic productivity and/or efficiency; and/or enhance sustainability, quality of life, and/or environmental justice..." As indicated by the definition, TDM seeks to induce behavioral changes on the generators of demand-which in the case considered in this paper are the receivers of the supplies and services - to increase the sustainability of the traffic that is created. TDM recognizes the role played by the receivers and accordingly, seeks to change the receivers' demand to reduce the externalities produced by the associated traffic [50]. TDM takes the same approach for parking as when dealing with congestion by impacting how receivers get their deliveries in order to distribute infrastructure in such a way that the demand is met in a more efficient manner. The authors' research has conclusively established that in a competitive market, the receivers have much influence over when, where, and how deliveries are made [50]. Since receivers are the customers, shippers/service providers/carriers that do not do the job in the manner desired by the receiver, run the risk of being replaced by more accommodating competitors. It is safe to assume that receivers have similar power in specifying the conditions to be met by service providers. This implies that public policies are aimed at inducing receivers-particularly those located in congested areasto change the timing, number, destination, and/or the mode used to make deliveries or receive a service.

The TDM strategies that will be a part of the policy discussion of this paper includes: Receiver-Led Consolidation Program-reduces the number of deliveries that arrives at a given location; Staggered Deliveries Program-deliveries are strategically distributed throughout work hours; and Off-hour Deliveres Program - switching deliveries to the off-hours (7 pm $-6 \mathrm{am})$. These initiatives provide plausible ways to reduce FSA traffic as they either aim to decrease the total number of FSA vehicles entering the area or impact the time at which the deliveries are made which decreases the number of the deliveries for a specific time period.

To quantify the impact of these TDM initiatives, several scenarios were analyzed. Since service trips contribute a small portion of the total trips and further research is needed to properly determine the relationships between the agents and which TDMs are suitable, it is assumed that they are not the target of TDM in this analysis. In increasing order of impacts, the scenarios are:

- Scenario 0 - Base Case: FSA trips arrive as current conditions without any TDM

- Scenario 1 - Receiver-Led Consolidation: it is assumed that all establishments reduce the number by one delivery/day. This scenario is in line with [50].

- Scenario 2-30\% Off-Hour Deliveries (OHD): 30\% of deliveries are switched to OHD.

- Scenario 3 - Staggered Deliveries: the deliveries are spread out throughout the working hours.

- Scenario 4-100\% Off-Hour Deliveries (OHD): all deliveries are switched to OHD.

Figure 2 shows the FSA parking needs for the different scenarios. As shown, the $100 \%$ OHD program is expected to be the most impactful as it reduces the parking needs by about $80 \%$ for the case of Troy, NY and approximately $70 \%$ for the SoHo case, during the peak morning hours $(6-8 \mathrm{am})$ compared to the base case-Scenario 0. In second place, Staggered Deliveries reduce parking needs during the peak morning hours by about $60 \%$ for both cases. The third place is occupied by the 30\% OHD Scenario and the Receiver-Led Consolidation programs, which are virtually tied, offering in the range of a $10-25 \%$ reduction in parking needs during the peak am hours.

These results have numerous implications worthy of discussion. First, they provide another indication of the 

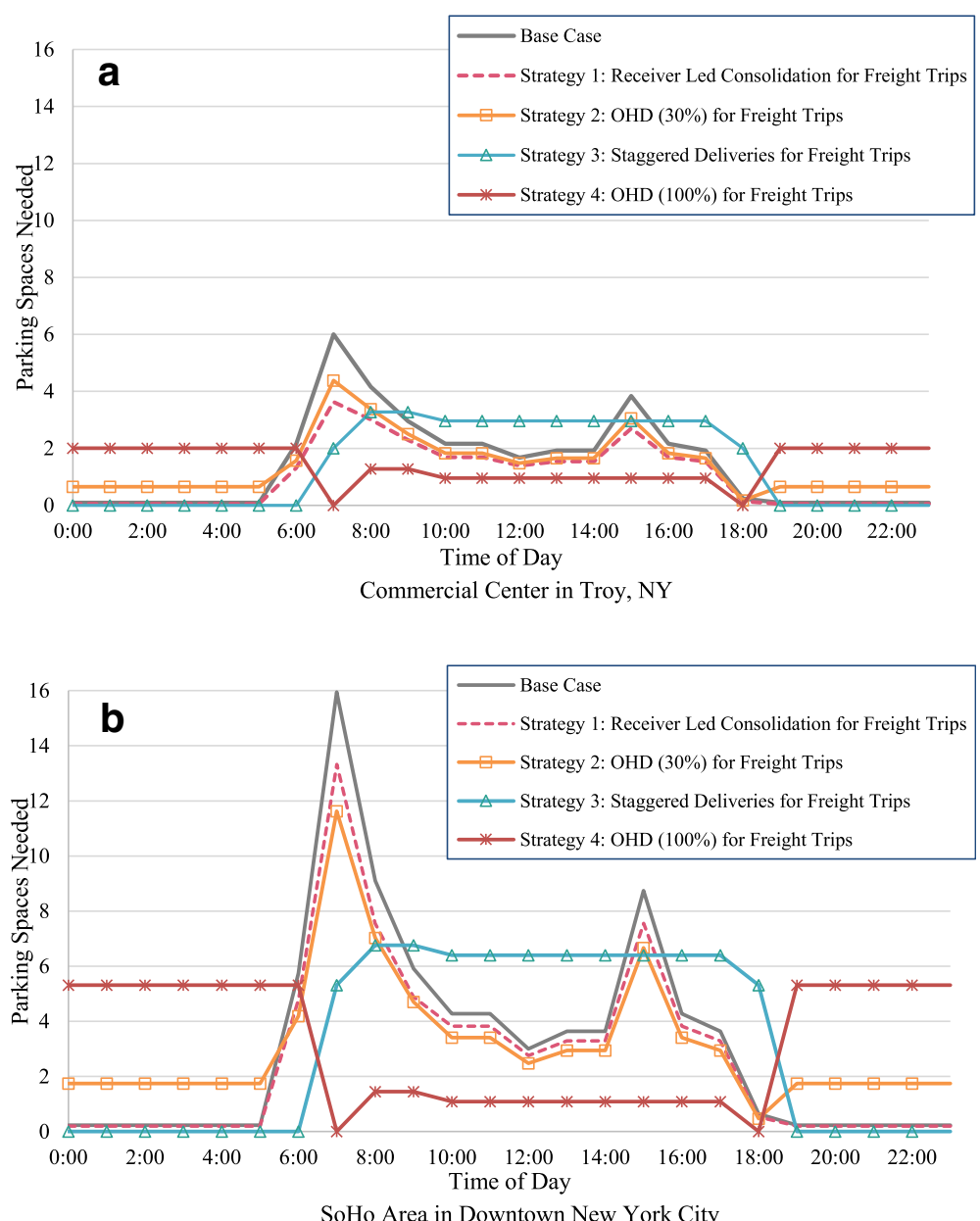

Fig. 2 Parking Space Needs vs. Transportation Demand Management Initiatives: a Commercial Center in Troy, NY; b SoHo Area in Downtown New York City

potential of area-focused OHD programs which could reduce parking needs in a substantial manner. Second, the results demonstrate the significant potential of Staggered Deliveries which if coordinated in a manner that will result in minimal disruption to receivers can have a major impact on parking needs. Receiver-Led Consolidation is also promising, particularly taking into account that $20 \%$ of establishments reported being willing to reduce the number of deliveries produced [50]. It is also important to analyze the impacts on the various agents involved. In the case of OHD, it has been established that it benefits both receivers and carriers though incentives to receivers are needed to overcome their initial resistance. It is not clear what kind of impacts Staggered Deliveries could produce. The authors' conjecture is that this could be inconvenient to receivers, which would be forced to accept deliveries during the hours they are busiest with customers; and slightly beneficial to carriers as it may lead to a more balanced use of their fleets. Receiver-Led Consolidation, as long as it is voluntary, could be beneficial to carriers and neutral to receivers. Further research is needed to identify in greater detail the impacts of the last three forms of TDM (i.e. strategies $2-4$ ) and the potential role of complementary policies to foster their use.

\subsection{Potential application to other cities}

The insights from this analysis may be applied to other cities, especially for cities that are highly dense and have the challenge of managing curb space with high demand, where solving the problem of limited parking spaces cannot be solved by adding infrastructure. This is true for many European cities as well, where over $75 \%$ of the population reside in cities [51]. European cities also tend to be older cities of which many were built with more narrow roads where there is already limited space for trucks to navigate. Many European cities are also walkable cities; hence, it is very important to properly manage the available parking spaces for FSA to ensure the smooth operation of FSA and maintain the walkability 
aspect. Therefore, TDM strategies can play a key role in achieving these goals of space management for many cities regardless of location. Cities such as Paris [52] have been dealing with similar issues to NYC and with increasing migration to urban areas the application of TDM strategies will assist in managing and supporting this growth as inevitably this increase in population also leads to increase in the demand for goods and as a result an increase in freight flows. Manhattan is a dense city with high land values which results in the many of the businesses within the space not having their own premises with a loading area; therefore, street parking is the main supply of parking for freight vehicles. Cities with similar conditions will be faced with addressing these issues in order to decrease the impact of delivery vehicles (e.g. congestion, pollution, and decrease in safety) within the network.

When considering implementation of TDM strategies it is important to tailor it to the specific city. Vital to fitting the strategy to the city is the estimation of the freight trip flows via freight trip generation models. For cities outside of the United States, the methodology used for the FTG models in the analysis is suitable. The reason being, that these models are based on the characteristics of the business operations and this is fairly consistent regardless of location. Attention should be paid to differences that may exist that prevent direct application of these FTG models, such as city size and policies in effect. To ensure the most accurate results, it is best to utilize the methodology of the FTG models used in this analysis and the data from the study location or country of interest. If local data are not available borrowing solid models, preferably from a comparable city and the appropriate industry sectors, will be more likely to influence better policy decisions than not having any FSA flow estimates.

\section{Conclusions}

The research reported in this paper utilized state of the art freight trip attraction and service trip attraction models to assess the parking needs of freight and service related commercial activities. The paper looked at two case studies: a commercial center in Troy, New York a midsize city; and commercial area in SoHo in Downtown New York City. The models were applied to these two cases to estimate the number of freight and service trips generated in a typical day by commercial establishments and then estimated the parking needs for four freight demand management strategies to see the effects on parking needs.

The initial analysis revealed the importance of parking duration as it was shown to be proportional to parking needs; the longer the duration the higher the need for parking. The simulations further bolstered this finding by showing that the optimal case (i.e. minimizing parking duration) occurs the closer the parking location is to the establishment. The further away the vehicle is parked the longer the walking time to the establishment, hence increasing the time the vehicle occupies the parking spot. For example, one block away from the establishment leads to a $44 \%$ increase in parking duration; and two blocks away leads to a $79 \%$ increase. This increase in parking duration results in an increase in the number of parking spots needed to fulfill demand as the wait time for parking spots is increased. The consequence of this is higher cruising times for vehicles, resulting in increased congestion and emissions on the network. Therefore, it is important for cities to allocate "local" parking areas for FSA, as it is more efficient.

This research analyzed the impact of Transportation Demand Management (TDM) strategies on FSA parking needs. As it is well recognized in previous research, TDM strategies are aimed at the agents with the power in order to effect behavior changes to increase sustainability within the system-in this case, meeting FSA parking needs. Of particular interest was the effect of these strategies on receivers, who have a greater influence in the frequency and timing of deliveries and service calls. The strategies applied to the case studies showed that TDM strategies are effective in decreasing the number of parking spots needed during peak periods. The most impactful of the strategies was shifting $100 \%$ of the freight trips to the off-hours as it reduced parking needs by $70-80 \%$ during the peak hours. Although this showed the most improvement to the current situation it maybe an unrealistic undertaking as it would require extreme changes to be put into effect. Staggered Deliveries for freight offered the second best impact, reducing peak demand by about $60 \%$. The strategy spreads out the deliveries in a uniformed manner resulting in less stress on the network during peak hours. This strategy though, will require significant effort in coordination and putting in place incentives to ensure receivers participation. The remaining strategiesReceiver-Led Consolidation (reduce number of deliveries/ day by one) and switching 30\% of freight trips to OHDoffer similar patterns throughout the day as the base case but they do offer significant decrease (10-25\%) during the peak hours with 30\% OHDs being a bit more impactful than Receiver-Led Consolidation.

Although the research has its limitations due to insufficient data and the use of assumptions; the authors tried to capture more realistic conditions. Hence, this study could be enhanced with more real data and empirical research in different urban areas. However, the results provide meaningful insights into parking and how to effectively manage the demand during peak periods. Further research is needed to identify in greater detail the impacts of the last three forms of TDM (i.e. strategies 2-4) and the potential role of complementary policies to foster their use. 


\section{Publisher's Note}

Springer Nature remains neutral with regard to jurisdictional claims in published maps and institutional affiliations.

\section{Author details}

'Department of Civil and Environmental Engineering, Rensselaer Polytechnic Institute, 110 8th St. JEC 4027, Troy, NY 12180, USA. ${ }^{2}$ Department of Civil Engineering, Universidad Nacional de Colombia at Medellin, Cl. 65 \#78-28. M1-110, Medellin, Colombia.

\section{Received: 20 January 2017 Accepted: 20 July 2018} Published online: 09 October 2018

\section{References}

1. Holguín-Veras J, Jara-Díaz S (1998) Optimal Pricing for Priority Service and Space Allocation in Container Ports. Trans Res Part B: Methodol 33(2):81106. https://doi.org/10.1016/S0191-2615(98)00029-0

2. Holguín-Veras J, Torres CA, Ban X (2013) On the comparative performance of urban delivery vehicle classes. Trans A Trans Sci 9(1):50-73

3. Jaller M, Holguín-Veras J, Hodge SD (2013) Parking in the City: challenges for freight traffic. Transp Res Rec 2379:46-56

4. Nourinejad M, Wenneman A, Nurul Habib K, Roorda MJ (2014) Truck parking in urban areas: application of choice modelling within traffic microsimulation. Transp Res A 64:54-64

5. Holguín-Veras J et al (2017) NCFRP report 37: using commodity flow survey microdata to estimate the generation of freight, freight trip generation, and service trips: guidebook," in "NCHRP/NCFRP. Transportation Research Board, Washington, D.C Available: https://www.nap.edu/catalog/24602/usingcommodity-flow-survey-microdata-and-other-establishment-data-toestimate-the-generation-of-freight-freight-trips-and-service-trips-guidebook

6. Ortúzar JD, Willumsen LG (2011) Modelling Transport, 4th edn. John Wiley and Sons, New York

7. Institute of Transportation Engineers (2008) Trip Generation, 7th edn. Institute of Transportation Engineers, Washington, D.C.

8. Cambridge Systematics (2007) Quick Response Freight Manual II. U.S. Department of Transportation. Federal Highway Administration, Washington, D.C 2007, vol. FHWA-HOP-08-010 EDL No. 14396

9. Cambridge Systematics (1996) Quick response freight manual. Federal Highway Administration, Washington DCDTFH61-93-C-00075 and DTFH6193-C-00216, September 1996

10. Harker PT (1985) The state of the art in the predictive analysis of freight transport systems. Transp Rev 5(2):143-164

11. M. H. E. Iding, W. J. Meester, and L. A. Tavasszy (2002) "Freight trip generation by firms," presented at the 42nd European congress of the European regional science association, Dortmund, Germany. Available: http://wuw-ruw.wu-wien.ac.at/ersa/ersaconfs/ersa02/cd-rom/papers/453.pdf

12. A. Heitz, T. Sakai, A. Beziat, and L. Dablanc, "Testing the 'freight landscape' concept for Paris," 2018. Available: https://www.researchgate.net/ publication/322820822_Testing_the_'Freight_Landscape'_Concept_for_Paris

13. Browne M, Allen J, Steele S, Cherrett T, McLeod F (2010) Analysing the Results of UK Urban Freight Studies. In: The Sixth International Conference on City Logistics, vol 2, pp 5956-5966 Procedia Social and Behavioral Sciences

14. Davydenko, I. Y., L. A. Tavasszy, J. J. Meijeren, and O. Ivanova (2011). Estimation of Freight Flow and Trip Generation According to Transport Purpose in Urban and Regional Logistics Networks. METRANS Urban Freight Conference, Long Beach, CA.

15. Novak DC, Hogdon C, Guo F, Aultman-Hall L (2008) Nationwide freight generation models: a spatial regression approach. Netw Spatial Econ

16. Regan AC, Garrido RA (2001) Modelling Freight Demand and Shipper Behaviour: State of the Art, Future Directions. Travel behaviour research-The leading edge, Pergamon, London, pp 185-215

17. Holguín-Veras J, Jaller M (2014) Comprehensive freight demand data collection framework for large urban areas. In: González-Feliu J, Semet F, Routhier JL (eds) Sustainable urban logistics: concepts, methods and information systems. Springer-Verlag, Berlin

18. M. Thornton, R. Guensler, and P. Schropp (1998) "Development of urban commercial vehicle travel model and heavy-duty vehicle emissions model for Atlanta region," presented at the proceedings of the 77th annual meeting of the Transportation Research Board, Washington, D.C.

19. Holguín-Veras J, López-Genao Y, Salam A (2002) Truck-Trip Generation at Container Terminals: Results from a Nationwide Survey. Trans Res Rec 1790(1):89-96
20. E. McCormack, C. Ta, A. Bassok, and E. Fishkin (2010) "Truck trip generation by grocery stores," transportation northwest regional center X (TransNow), Seattle, WA

21. Transportation Engineering and Planning Inc (2003) "Truck trip generation study," City of Fontana County of San Bernardino, State of California

22. Bastida C, Holguín-Veras J (2009) Freight Generation Models: Comparative Analysis of Regression Models and Multiple Classification Analysis. Trans Res Rec 2097:51-61. https://doi.org/10.3141/2097-07

23. Brogan JD (1980) Improving truck trip-generation techniques through tripend stratification. Transp Res Rec 771:1-6

24. Sánchez-Díaz I, Holguín-Veras J, Wang X (2016) An exploratory analysis of spatial effects on freight trip attraction. (in English), Transportation 43(1):177-196

25. Lawson C, Holguín-Veras J, Sánchez-Díaz I, Jaller M, Campbell S, Powers E (2012) Estimated generation of freight trips based on land use. Trans Res Record 2269:65-72

26. Khan M (2015) Application of choice modeling methods to describe commercial vehicle travel behavior in urban areas. Doctor of Philosophy, The University of Texas at Austin

27. Zavattero D, Weseman S (1981) Commercial vehicle trip generation in the Chicago region. Transp Res Rec 834:15

28. Holguín-Veras J, Jaller M, Destro L, Ban X, Lawson C, Levinson HS (2011) Freight generation, freight trip generation, and perils of using constant trip rates. Trans Res $\operatorname{Rec} 2224(1): 68-81$

29. Ha D-H, Combes F (2016) Building a model of freight generation with a commodity flow survey. In: Clausen U, Friedrich H, Thaller C, Geiger C (eds) Commercial transport: proceedings of the 2nd interdisciplinary conference on production, logistics and traffic 2015. Springer, Switzerland, pp 23-37

30. Anderson S, Allen J, Browne M (2003) Service Related Vehicle Activity in Urban Areas. In: Taniguchi E, Thompson R (eds) City Logistics II. Institute for City Logistics, pp 1st, 335-349st

31. Wigan M, Browne M, (2002) Understanding the growth in service trips and developing transport modelling approaches to commercial, service and light goods movements. Presented at the European transport conference, Cambridge Available: https://trid.trb.org/view.aspx?id= 726966

32. Holguín-Veras J et al (2012) NCHRP Report 739 / NCFRP Report 19: Freight Trip Generation and Land Use. In: National Cooperative Highway Research Program / National Cooperative Freight Research Program. Transportation Research Board, Washington D.C NCHRP Report 739/NCFRP Report 19, Available: http://onlinepubs.trb.org/onlinepubs/nchrp/nchrp_rpt_739.pdf, Accessed on: 02/06/2014

33. Holguín-Veras J et al (2013) Transferability of freight trip generation models. Trans Res Rec 2379:1-8

34. Institute for Transportation and Development Policy -ITDP (2010) U.S. Parking Policies: An Overview of Management Strategies, New York Available: https://www.itdp.org/u-s-parking-policies-an-overview-ofmanagement-strategies/

35. Technical Committee of Transport (2005) Parking Policies and the Effects on Economy and Mobility. In: Report on COST Action 342. COST Available: http:// www.europeanparking.eu/media/1207/cost-action-342-final-report-1.pdf

36. Odani M, Tsuji T (2001) Experiment to Demonstrate the Effectiveness of Onstreet Parking Facilities for Delivery Vehicles. In: Taniguchi E, Thompson R (eds) City Logistics II, pp 351-366

37. Muñuzuri J, Larrañeta J, Onieva L, Cortés P (2005) Solutions Applicable by Local Administrations for Urban Logistics Improvement. Cities 22(1):15-28. https://doi.org/10.1016/j.cities.2004.10.003

38. New York City Department of Transportation (2015) Motorists \& Parking Parking a Truck or Commercial Vehicle. Available: http://www.nyc.gov/html/ dot/html/motorist/parktruck.shtml

39. J. Holguín-Veras et al. (2013) Integrative freight demand management in the New York City Metropolitan Area: implementation phase. Rensselaer Polytechnic Institute, New York City Department of Transportation, Rutgers UniversityRITARS-11-H-RPI, Available: http://cite.rpi.edu/news/16-off-hourdelivery

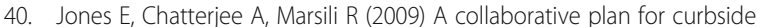
freight delivery in Washington D.C. ITE J 79(5):22-25

41. San Francisco County Transportation Authority (2009) "On-Street Parking Management and Pricing Study: Final Report," Available: http://www.sfcta. org/sites/default/files/content/Planning/ParkingManagementStudy/pdfs/ parking_study_final.pdf 
42. E. Marcucci, V. Gatta, and L. Scaccia (2015) "Urban freight, parking and pricing policies: an evaluation from a transport Provider's perspective," Transp Res A Policy Pract 74, no. 0, pp. 239-249

43. Dablanc $L$ (2007) Goods Transport in Large European Cities: Difficult to Organize, Difficult to Modernize. Trans Res Part A Pol Pract 41(3):280-285. https://doi.org/10.1016/j.tra.2006.05.005

44. Huschebeck M (2004) BEST Urban Freight Solutions: Deliverable D1.4 Recommendations for Further Activities. Best Urban Freight Solutions (BESTUFS)

45. Garcia Ramon J (2001) Urban freight distribution in Barcelona," in "Best urban freight solutions conference, vol 2001. Ajuntament de Barcelona Available: http://www.bestufs.net/download/conferences/Barcelona March01/BESTUFS_Barcelona_March01_Ramon_Barcelona.pdf

46. PIARC (2012) Public Sector Governance of Urban Freight Transport. World Road Association PIARC Available: http://www.piarc.org/en/order-library/17001-enPublic\%20sector\%20governance\%20over\%20urban\%20freight\%20transporthtm

47. U.S. Census Bureau (2016). "USA Counties." Data File Downloads. Posted, 29 December 2016, from https://www.census.gov/support/ USACdataDownloads.html

48. U.S. Census Bureau (2016). "County Business Patterns: 2014." Posted, 21 July 2016, Retrieved 29 December 2016, from https://www.census.gov/data/ datasets/2014/econ/cbp/2014-cbp.html

49. Holguín-Veras J, Silas MA, Polimeni J, Cruz B (2007) An investigation on the effectiveness of joint receiver-carrier policies to increase truck traffic in the off-peak hours: part I: the behaviors of receivers. Netw Spatial Econ 7(3): 277-295

50. Holguín-Veras J, Sánchez-Díaz I (2016) Freight Demand Management and the Potential of Receiver-Led Consolidation Programs. Trans Res A 84:109-130

51. Dezi G, Dondi G, Sangiorgi C (2010) Urban Freight Transport in Bologna: Planning Commercial Vehicle Loading/Unloading Zones. In: The Sixth International Conference on City Logistics, Bologna, Italy, pp 5990-6001 Procedia Social and Behavioral Sciences

52. Beziat, A. (2015). Parking for Freight Vehicles in Dense Urban Centers: The Issue of Delivery Areas in Paris. Transportation Research Board 94th Annual Meeting. Washington DC

\section{Submit your manuscript to a SpringerOpen ${ }^{\circ}$ journal and benefit from:}

- Convenient online submission

- Rigorous peer review

- Open access: articles freely available online

- High visibility within the field

- Retaining the copyright to your article

Submit your next manuscript at $\boldsymbol{\nabla}$ springeropen.com 